\title{
Análisis socioambiental de las playas Puerto Velero y Caño Dulce en Tubará, Atlántico, Colombia
}

Franklin Torres Bejarano

Rubén Cantero Rodelo Universidad de la Costa Barranquilla, Colombia

Beatriz Díaz-Solano Jina Marcela Mendoza Lozano Yeimi Fernanda López Mejía Universidad Autónoma del Caribe Barranquilla, Colombia

\section{Resumen}

Este trabajo presenta resultados de un proyecto de investigación que tiene por objetivo determinar indicadores sociales y ambientales que afectan la calidad del agua de las playas de Puerto Velero y Caño Dulce en el municipio de Tubará, Atlántico, Colombia. Los monitoreos se realizan una vez al mes en tres puntos a lo largo de las dos playas. Entre octubre de 2012 y abril de 2013, se han realizado siete monitoreos en el aspecto social, de parámetros como: servicios domiciliarios, tenencia de propiedad, impuestos al municipio, número de trabajos en las casetas y ocupación de visitantes; y en lo ambiental los parámetros $\mathrm{pH}$, oxígeno disuelto, conductividad, sólidos disueltos totales, grasas y aceites, coliformes totales y fecales. Los resultados de las mediciones y análisis fisicoquímicos muestran que la calidad del agua en estas playas presenta niveles aceptables, sólo en casos aislados se sobrepasan los límites establecidos por la normativa nacional.

\section{Palabras clave}

Calidad del agua, playas turísticas, calidad del agua, indicadores ambientales, indicadores sociales. 


\title{
Socio-environmental analysis of the Puerto Valero and Caño Dulce beaches in Tubará, Atlantico, Colombia
}

\begin{abstract}
Abstrac
This paper presents results of an ongoing research project that aims to determine social and environmental indicators that affect water quality of Puerto Velero beach and Caño Dulce beach in Tubará, Atlántico, Colombia. The monitoring is carried out once a month at three points along the two beaches. So far, 7 monitoring campaigns from October 2012 to April 2013 have been carried out, measuring social aspects as: Residential Services, Possession of Property, the Municipality Tax, Number of Jobs in the sheds and Occupation of visitors; and environmental parameters like $\mathrm{pH}$, dissolved oxygen, conductivity, total dissolved solids, oils and grease, total and fecal coliforms. The measurements results and physicochemical analyzes show that the water quality at these beaches has acceptable levels, only in specific cases exceed the permissible limits established by national law.
\end{abstract}

Franklin Torres Bejarano

Rubén Cantero Rodelo Universidad de la Costa Barranquilla, Colombia

Beatriz Díaz-Solano Jina Marcela Mendoza Lozano Yeimi Fernanda López Mejía Universidad Autónoma del Caribe Barranquilla, Colombia

\section{KEY WORDS}

Water quality, touristic beaches, environmental indicators, social indicators

Correos electrónicos: ftorres4@cuc.edu.co / rcantero@cuc.edu.co / beatriz.diaz@uac.edu.co / jinamarcela.mendoza@uac.edu.com / yeimi.lopez@uac.edu.co 


\section{Introducción}

La calidad del agua en las playas es muy importante, sobre todo cuando su uso es con fines recreativos, debido a que las personas pueden estar expuestas a patógenos a través de la ingestión, inhalación o contacto con la piel. Los patógenos responsables de producir enfermedades pueden ser bacterias, virus, protozoarios, hongos o parásitos que viven en el tracto gastrointestinal de animales de sangre caliente (López et al., 2009).

Sin embargo, debido a las dificultades en los análisis para detectar los posibles microorganismos patógenos, se usan como indicadores primarios de contaminación fecal las concentraciones de bacterias coliformes totales, coliformes fecales (Environmental Protection Agency, 2003). Los parámetros físico químicos también juegan un papel muy importante en la calidad de las playas ya que son un fuerte indicador del estado del cuerpo de agua.

La participación de la comunidad desde las primeras etapas del desarrollo turístico es fundamental para su éxito y para minimizar los problemas económicos (Oyarzún y Szmulewicz, 1999). El gobierno de Colombia busca promover la formalización de las actividades económicas que se desarrollan en las playas, a través de modelos que optimicen los flujos financieros y aseguren la sostenibilidad del negocio turístico. No obstante, el crecimiento de la actividad turística no planificada, junto a la falta de un adecuado manejo de las playas, está generando la degradación de estos recursos, causando no solamente una pérdida económica, sino una gran pérdida ecológica y cultural (Ministerio de Comercio, Industria y Turismo, 2011).

Debido a que el turismo se enmarca en el sector servicios y que dichos servicios se dan por personas y para personas, los dos elementos más importantes a estudiar y tener en cuenta en el futuro son los trabajadores del sector y los turistas (García y Martínez, 2008). El área de estudio está enmarcada en las playas de Puerto Velero y Caño Dulce, ubicadas en el municipio de Tubará, Atlántico, donde también confluyen zonas ecotonales, relieves colinados, planicies fluviomarinas y planicies fluviales, frente al mar Caribe, con un gran potencial turístico, y cuyas playas se han convertido en sitio de recreación de los habitantes de 
Barranquilla y de los municipios cercanos. Sin embargo, todavía existen muchos kilómetros de playas sin aprovechar y las que se utilizan no tienen las condiciones adecuadas para prestar un buen servicio al turista (Osorio, 2011). La figura 1 muestra la ubicación geográfica del área de estudio y una panorámica de las playas estudiadas.
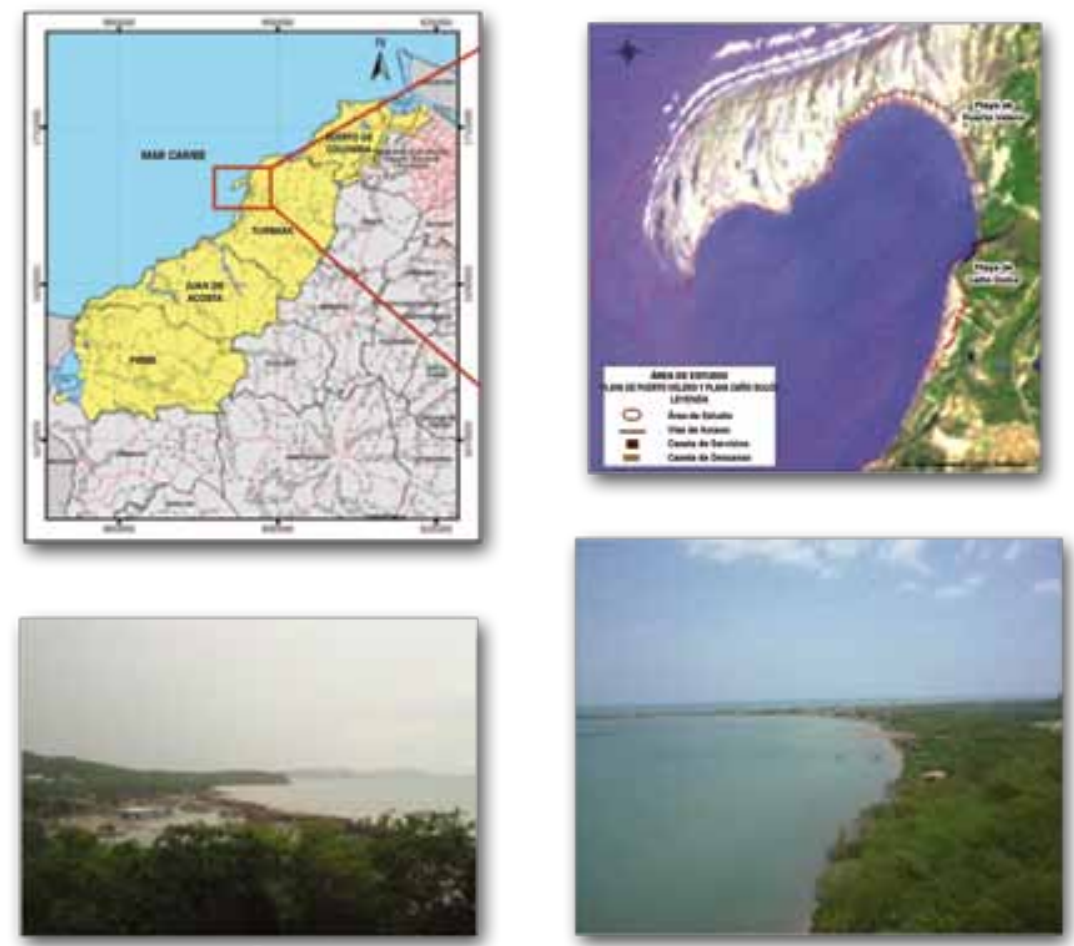

PLAYA DE CAÑO DULCE

PLAYA DE PUERTO VELERO

Figura 1. Zona de estudio 


\section{Antecedentes}

El departamento del Atlántico cuenta con una extensión de zona costera de $64.5 \mathrm{~km}$, la cual representa $4 \%$ del Caribe colombiano, incluye los municipios de Puerto Colombia, Tubará, Piojó, Juan de Acosta, Luruaco y el Distrito Especial, Industrial y Portuario de Barranquilla. Las playas de Puerto Velero y Caño Dulce pertenecen al municipio de Tubará, son playas de arena oscura o parda, muy expuestas a los vientos estacionales y con gran influencia de recepción de sedimentos por la cercanía con la desembocadura del río Magdalena. La contaminación bacteriana de las aguas costeras es causada por una combinación de fuentes puntuales y no puntuales. Si bien las fuentes puntuales de contaminación bacteriana (por ejemplo la industria y las instalaciones de tratamiento de aguas servidas) son significativas, las fuentes no puntuales de contaminación representan una amenaza mucho mayor para la integridad de las masas de agua recreativas pues contienen una mezcla diversa de contaminantes químicos y biológicos, además de que se descargan desde numerosos sitios indefinidos dentro de una determinada cuenca.

Estudios iniciales indican que el sector de Puerto Velero y Caño Dulce no cuenta con los servicios de acueducto, alcantarillado, sistemas para disposición correcta de basuras, ni con estrategias necesarias para el manejo ambiental, lo que genera un factor de riesgo para la calidad del agua y la arena de playa, pudiendo convertirse éste en un problema de salud pública debido a la alta afluencia de bañistas los fines de semana y temporadas de vacaciones.

En las playas del departamento del Atlántico, los prestadores de los servicios turísticos son en su gran mayoría habitantes del propio municipio o municipios cercanos que desarrollan la labor de manera artesanal, con poca preparación y con una baja gestión gubernamental, su presencia en el lugar en un porcentaje de 65 a 70\% es exclusiva en los días de presencia de los turistas (fines de semana y días festivos). El aspecto social es una variable que debe estudiarse en conjunto con los aspectos de calidad del agua, pues es reconocido que la presencia de residentes y visitantes, unidos al manejo de desechos y a los conceptos de posesión del lugar y su identidad, generan consecuencias que pueden ser favorables o desfavorables ambientalmente para el área de influencia. 


\section{Materiales y métodos}

\section{Toma de muestras}

Las muestras ambientales fueron tomadas una vez al mes en tres puntos a lo largo de las dos playas estudiadas. Hasta el momento, se han realizado siete campañas de monitoreo correspondientes a los meses de octubre, noviembre, diciembre de 2012, y enero, febrero, marzo y abril de 2013. Abarcando la temporada alta de las vacaciones de fin de año. De cada punto de muestreo se tomaron dos muestras de agua, a las 10:00 a.m y a las 4:00 p.m, aproximadamente.

Las muestras fueron tomadas a 20 y 25 metros de la orilla, a una profundidad de $30 \mathrm{~cm}$ por debajo de la superficie del agua. Todas las muestras fueron preservadas bajo refrigeración en hieleras, hasta ser trasladadas al laboratorio del Centro de Investigaciones en Tecnologías Ambientales (CіTA), de la Universidad de la Costa.

Para cubrir la recolección de información en el aspecto social, en cada uno de los días de muestreo se realizó el conteo total de visitantes y se identificó la cantidad de vehículos y sus modelos. La recolección de información se hizo mediante la aplicación de entrevistas y bajo observación. Se encuestó al 66\% de la población (caseteros) y se aplicaron 51 encuestas (Puerto Velero 24 y Caño Dulce 27).

\section{Variables in situ}

La mediciones de $\mathrm{pH}$, temperatura, oxígeno disuelto, sólidos disueltos totales, conductividad y salinidad se realizaron in situ con un equipo multiparamétrico marca WTW- MPP 350.

\section{Análisis fisicoquímicos}

En el laboratorio se determinaron las variables fisicoquímicas como turbiedad, color, grasas y aceites según las técnicas recomendadas de los 
métodos normalizados de American Public Health Association (APHA)American Water Works Association (AwwA) (1992). La turbiedad se realizó por el método turbidimétrico con un turbidímetro portátil marca $2100 \mathrm{Q}$ $\mathrm{HACH}$, las grasa y aceites se realizaron por el método gravimétrico con un cuerpo soxhlet.

\section{Análisis bacteriológicos}

Para los recuentos de coliformes totales y fecales en las muestras de aguas, se utilizó el método de filtración por membrana (APHA, AWWA, APCF, 1992).

\section{Resultados y discusión}

\section{Análisis fisicoquímicos}

pH. La variación del pH mostró un patrón común en las dos playas. Los valores de $\mathrm{pH}$ estuvieron en un margen de variación de 8.0 a 8.27 en la playa de Puerto Velero; y de 7.57 a 8.20 en la playa de Caño Dulce (figura 2).

Los valores de $\mathrm{pH}$ más bajos fueron observados durante el periodo de octubre de 2012 y marzo de 2013, en los puntos de muestreo de las playas analizadas. Mientras que los valores de $\mathrm{pH}$ más altos se presentaron en el mes de enero de 2013 en las dos playas.

Según la normatividad colombiana que regula los valores admisibles para el uso del recurso hídrico para fines de recreación, el nivel de $\mathrm{pH}$ debe estar comprendido entre 5 y 9 , por lo que los valores obtenidos cumplen con este requerimiento (Ministerio de Agricultura, 1984).

Temperatura. En la playa de Puerto Velero la temperatura mínima fue de $25.5^{\circ} \mathrm{C}$ registrada en enero del 2013 , mientras que la máxima fue de $30.5^{\circ} \mathrm{C}$, en octubre del 2012. Para la playa Caño Dulce el rango de temperaturas es de $26.3^{\circ} \mathrm{C}$ registrado en enero del 2013 a $30.9^{\circ} \mathrm{C}$ registrado en octubre del 2012; no se establece 

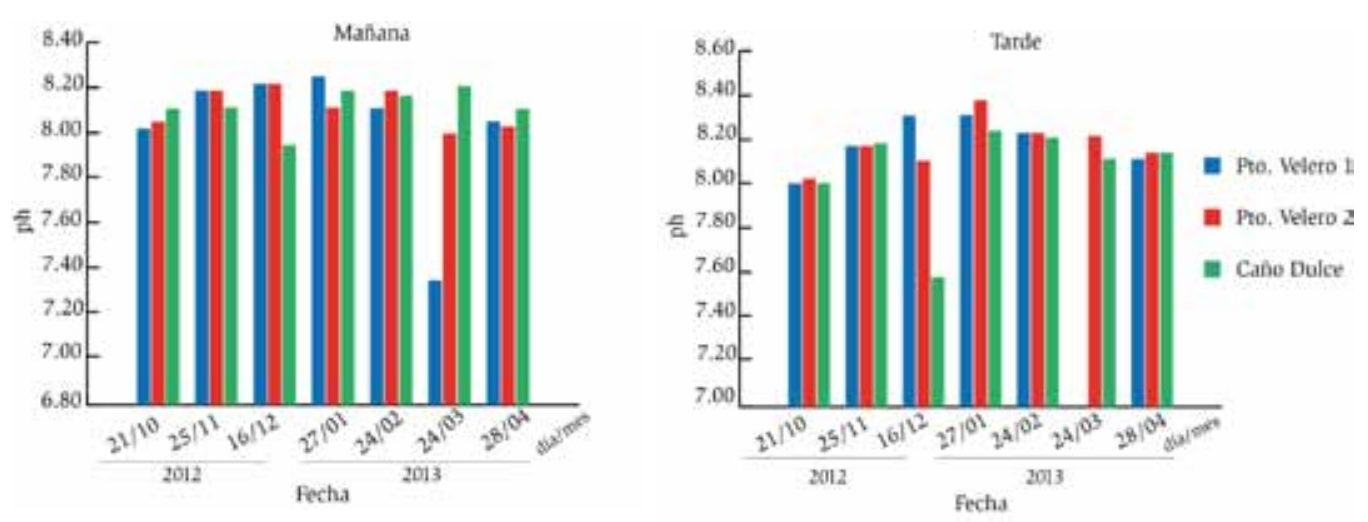

FIgURA 2. Valores de pH en las tres estaciones de medición

un valor o rango de valores admisibles para este parámetro en la normativa colombiana, sin embargo, estas temperaturas no tienen grandes variaciones a lo largo del tiempo de muestreo y son consistentes con los valores esperados para las zonas costeras situadas cerca del ecuador.

Oxígeno disuelto. En la playa de Puerto Velero el valor mínimo de oxígeno disuelto fue de $3.75 \mathrm{mg} / \mathrm{L}$ para octubre del 2012, y el valor máximo fue de 8.61 mg/L para enero del 2013; mientras que para la playa de Caño Dulce el oxígeno disuelto mínimo registrado fue de $3.8 \mathrm{mg} / \mathrm{L}$ en octubre del 2012 y el valor máximo, $6.95 \mathrm{mg} / \mathrm{L}$, se presentó en enero del 2013 (figura 3). En una correlación con los datos de temperatura se puede observar que para la playa de Puerto Velero a medida que la temperatura disminuye el oxígeno disuelto aumenta.

Según el decreto 1594 de 1984 el valor de oxígeno disuelto aceptado para el agua de uso recreacional es de $70 \%$ de la concentración de saturación; según MetCalf y Eddy (1995) realizando una interpolación con datos conocidos, para el agua de Puerto Velero a $29{ }^{\circ} \mathrm{C}$ con un contenido de salinidad de $33.7 \mathrm{ppt}$, la concentración de saturación de oxigeno es de $6.37 \mathrm{mg} / \mathrm{L}$, como el valor permitido es $70 \%$; la concentración de oxígeno disuelto debe ser de $4.459 \mathrm{mg} / \mathrm{L}$.

El agua de Caño Dulce con una temperatura de $29.6{ }^{\circ} \mathrm{C}$ y una salinidad de 33,67 ppt el oxígeno disuelto saturado es de $6.34 \mathrm{mg} / \mathrm{L}$; la concentración aceptada 
es de $4.44 \mathrm{mg} / \mathrm{L}$, correspondiente a $70 \%$ de la concentración saturada; esto quiere decir, entonces, que la concentración de oxígeno disuelto se excede, de lo aceptado según la normativa, también para esta playa.
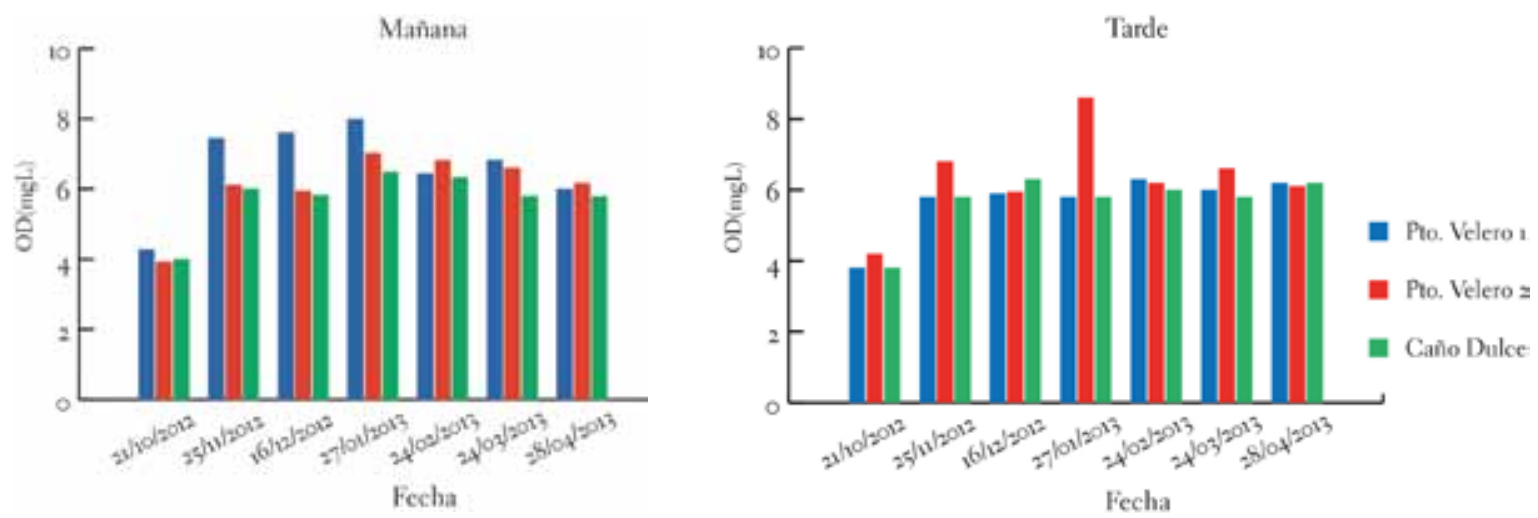

Figura 3. Valores de oxígeno disuelto en las tres estaciones de medición

Solidos disueltos totales. Para la playa de Puerto Velero los valores encontrados oscilaron entre 31.20 y $35 \mathrm{mg} / \mathrm{L}$ con un valor promedio de $32.58 \mathrm{mg} / \mathrm{L}$; sin embargo en la playa de Caño Dulce, para las horas de la tarde se midió una mayor concentración de sólidos disueltos que en la mañana, obteniéndose un valor máximo de $53.60 \mathrm{mg} / \mathrm{L}$, medido en horas de la tarde en octubre de 2012 y un valor mínimo de $31.40 \mathrm{mg} / \mathrm{L}$. medido en la misma fecha para horas de la mañana. El promedio de sólidos disueltos totales para esta playa fue de $42.83 \mathrm{mg} / \mathrm{L}$.

Grasa y aceites en agua. Las fluctuaciones en estos valores son altas, por lo que la aplicación de un promedio aritmético no presentaría resultados confiables; para todos los puntos de muestreo tanto en horas de la mañana como en horas de la tarde los valores máximos se obtuvieron entre octubre y noviembre del 2012 (figura 4); para estas fechas específicas el valor máximo registrado fue de $860 \mathrm{mg} / \mathrm{L}$ para la playa de Puerto Velero y de $662 \mathrm{mg} / \mathrm{L}$ para la playa de Caño 
Dulce; para diciembre de 2012 y enero del 2013 los valores disminuyeron, obteniéndose un máximo de $44.1 \mathrm{mg} / \mathrm{L}$ para enero de 2013 en la playa de Puerto Velero y de $35.1 \mathrm{mg} / \mathrm{L}$ para la playa de Caño Dulce; es probable que la alta presencia de grasas y aceites en las playas durante estas fechas se deba a la incidencia de la práctica de deportes acuáticos que requieren para su desarrollo la utilización de combustibles.
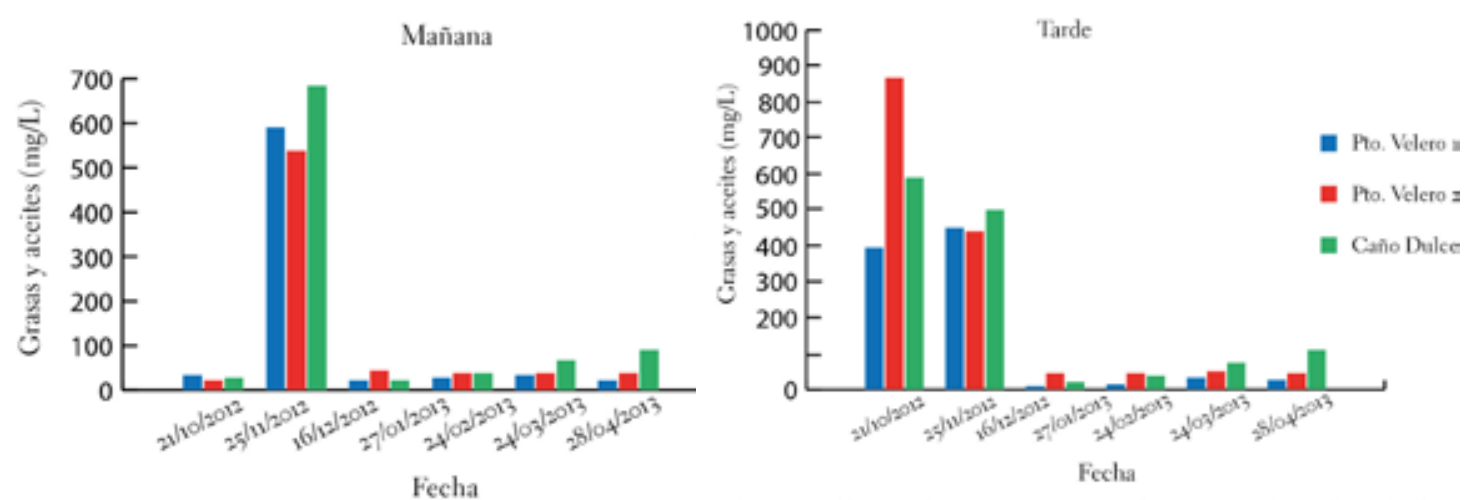

FiguRa 4. Valores de grasas y aceites en las tres estaciones de medición

Sólidos suspendidos totales. Para ambas playas durante todos los horarios de muestreo los valores mínimos de sólidos totales se obtuvieron en diciembre de 2012 y en abril de 2013; mientras que los máximos se obtuvieron en enero del 2013; el valor máximo obtenido en Puerto Velero fue de $1702 \mathrm{mg} / \mathrm{L}$ y en Caño Dulce de $2068 \mathrm{mg} / \mathrm{L}$ (figura 5); debido a que los sólidos suspendidos totales pueden ser de origen animal, vegetal o de origen terrígeno arrastrado por escorrentía se asume que la gran cantidad de turismo propio de la época es la causa de la gran concentración de los sólidos suspendidos totales que se observa en enero de 2013 (López et al., 2009). 

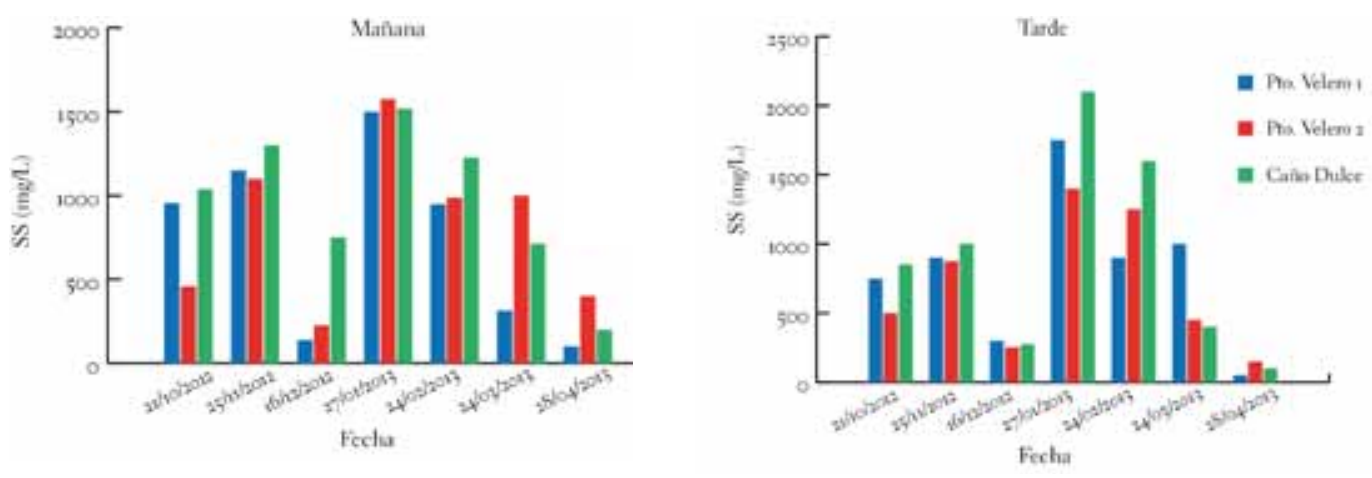

FiguRA 5. Valores de sólidos suspendidos totales en las tres estaciones de medición

Coliformes totales. Para la playa de Puerto Velero el contenido de coliformes totales oscila entre cero y $39 \mathrm{UFC} / 100 \mathrm{ml}$, mientras que para la playa de Caño Dulce el valor máximo es de $62 \mathrm{UFC} / 100 \mathrm{ml}$. Estos valores cumplen con los 1000 UFC/100 ml establecidos como valor máximo de coliformes totales en el decreto 1594 de 1984; sin embargo, su presencia es un indicio de que el agua puede estar contaminada con aguas negras u otro tipo de desechos en descomposición; la cantidad de coliformes detectadas puede deber su origen a que su acumulación se da principalmente en la superficie del océano y en el fondo del lecho marino.

Coliformes fecales. Su presencia en el agua de la playa de Puerto Velero comprende un rango entre 0 y $18 \mathrm{UFC} / 100 \mathrm{ml}$, mientras que para la playa de Caño Dulce este valor oscila entre 0 y $33 \mathrm{UFC} / 100 \mathrm{ml}$ (figura 6); ambos valores cumpliendo con lo establecidos por la normativa colombiana para aguas de recreación con contacto primario (Ministerio de Agricultura, 1984), debido a que la presencia de coliformes fecales en el agua es un buen indicador de contaminación por aguas negras, es apropiado inferir que el agua de la playa Caño Dulce presenta mayor contaminación por aguas negras debido a sus valores superiores lo cual implica riesgos a la salud a pesar de su cumplimiento con la normativa. 

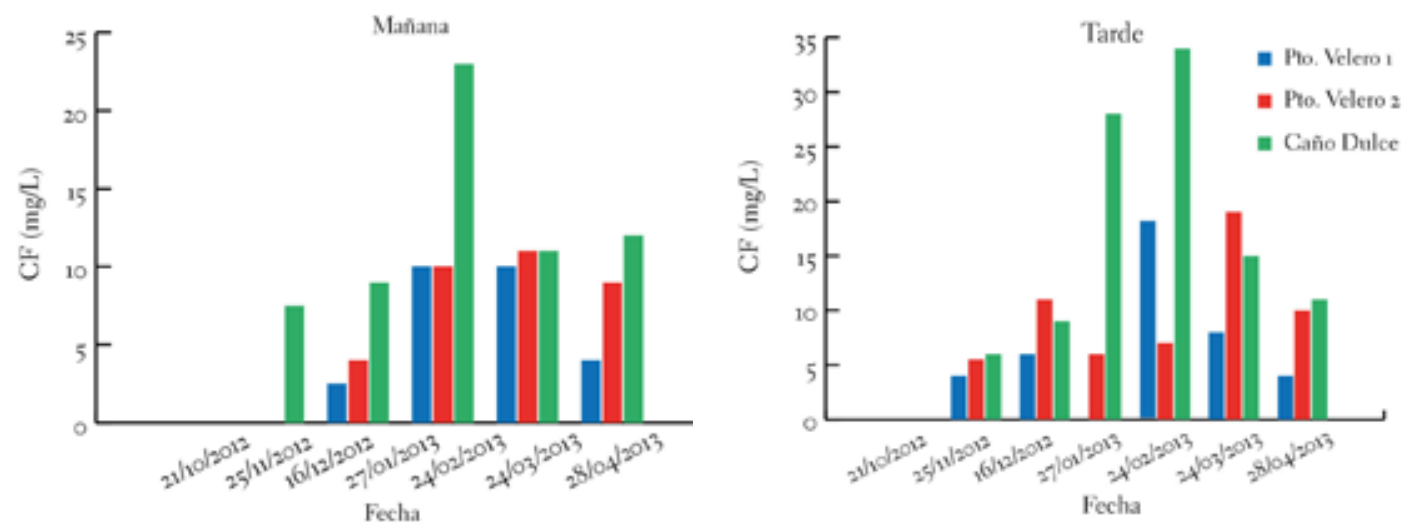

FiguRa 6. Valores de los coliformes fecales en las tres estaciones de medición

\section{Análisis social}

En cuanto al suministro de energía eléctrica en las playas (figura 7), 89.5\% de los caseteros de Caño Dulce cuentan con energía eléctrica; en lo que respecta a Puerto Velero lleva escasos seis meses con el servicio de energía, siendo esta una gestión del sector privado, que ejerce presión para la puesta en marcha de un complejo turístico.

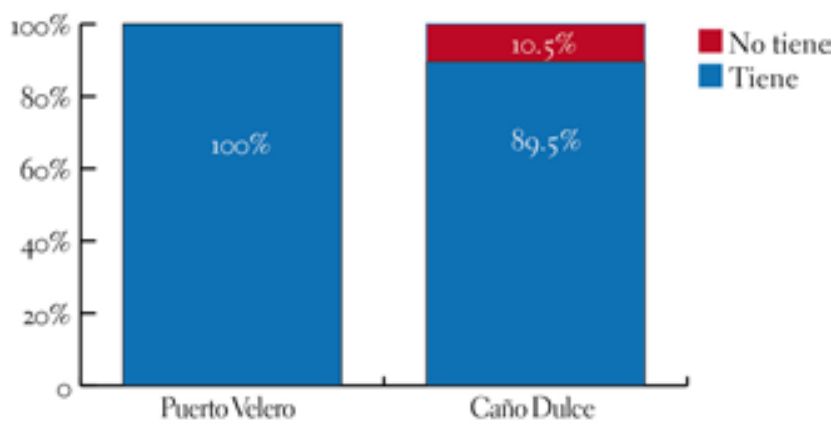

Figura 7. Suministro de energía 
Un servicio básico de responsabilidad gubernamental es el agua potable, estas playas no cuentan con este servicio, los prestadores de servicios deben valerse de medios alternativos para provisionarse del agua necesaria (figura 8), el mayor porcentaje se abastecen de otros municipios (78.9 \% Caño Dulce y 66.7 \% Puerto Velero); sólo $13.3 \%$ de los caseteros de Puerto Velero, usan el aguas de lluvia como fuente de abastecimiento.

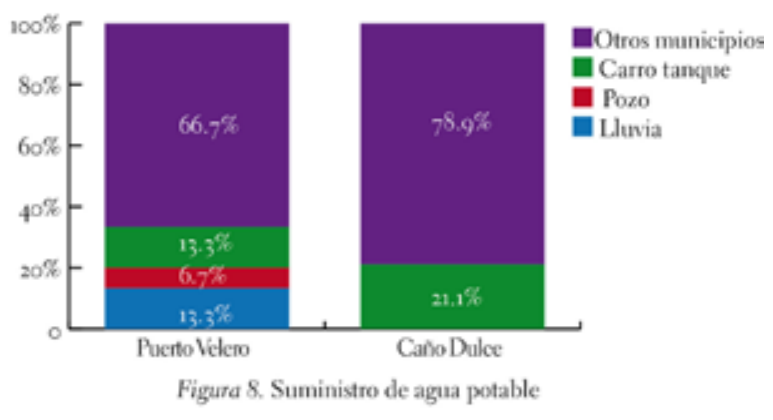

Las dos playas se encuentran desprovistas del servicio de alcantarilla. Al indagar por la manera en que se presta el servicio de sanitario a los turistas, se precisó que en Puerto Velero $73.3 \%$ de los caseteros cuenta con baños, siendo estos pozo sépticos o baños ecológicos que el gobierno les ha suministrado, son compartidos a razón de un baño por cada dos casetas. Por su parte, todas las casetas que prestan servicio en Caño Dulce cuentan con baños para el servicio a los turistas (figura 9), pero es un servicio de baja calidad al no contar con agua potable o alcantarillado.

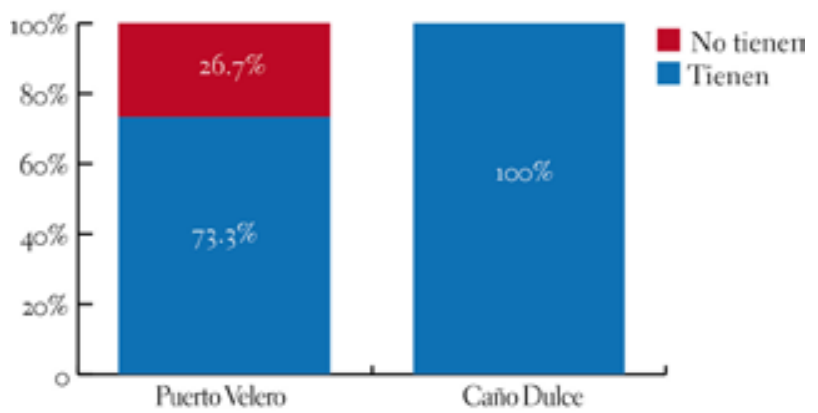

Figura 9. Servicio sanitario 
En el manejo de residuos, estas playas sólo reciben el servicio público de recolección de basuras una vez al mes, por lo que los caseteros deben realizar su propia recolección y definir el destino final de manera particular. Al indagar si los caseteros realizan aseo en playa y lugar de trabajo, se encontró que, tanto en Puerto Velero como en Caño Dulce, la mayoría de los caseteros si realiza recolección, $93.3 \%$ y $89.5 \%$ respectivamente (figura 10 ).

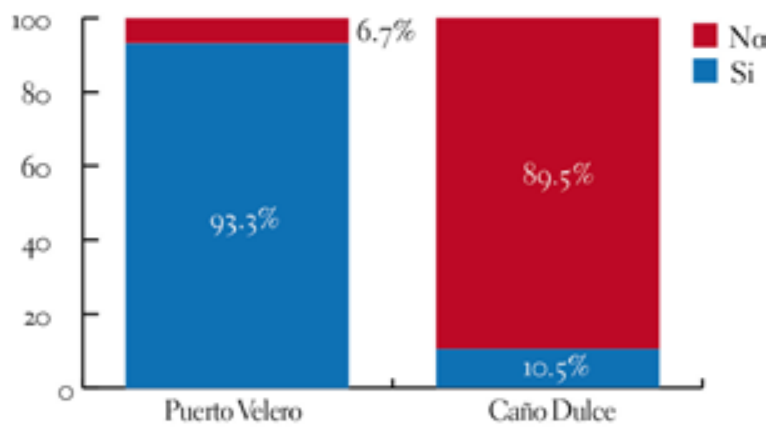

Figura 10. Recolección de basura

En la disposición final de los residuos sólidos (figura 11), se observa que la quema a cielo abierto es el primer mecanismo, el proceso de enterrar basura se hace de manera rudimentaria, sin ningún tipo de separación o de preparación del terreno, por lo que estas actividades generan una alta contaminación y degradación del suelo, el reciclaje sólo se presenta en vidrio y latas. Estas situaciones se deben a una falta de capacitación a los prestadores de los servicios.

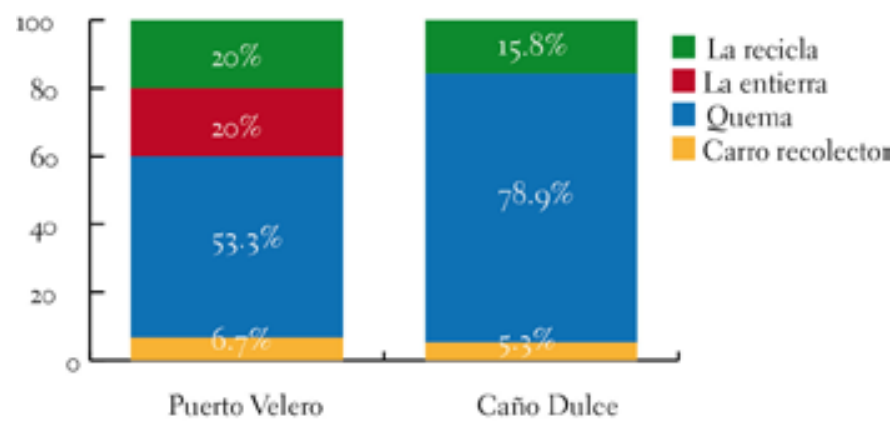

Figura 11. Disposición de residuos sólidos 
En cuanto a la posesión de los inmuebles, se pudo verificar que $72.4 \%$ de las personas son los poseedores legales del inmueble por concesión. Caño Dulce presenta mayor porcentaje de concesión 94.8\% (figura 12) debido a que algunos prestadores de servicios tienen su domicilio permanente allí, a diferencia de Puerto Velero que sólo es ocupado el día de actividad, desplazándose estas personas desde los municipios de Tubará, Puerto Colombia y Barranquilla.

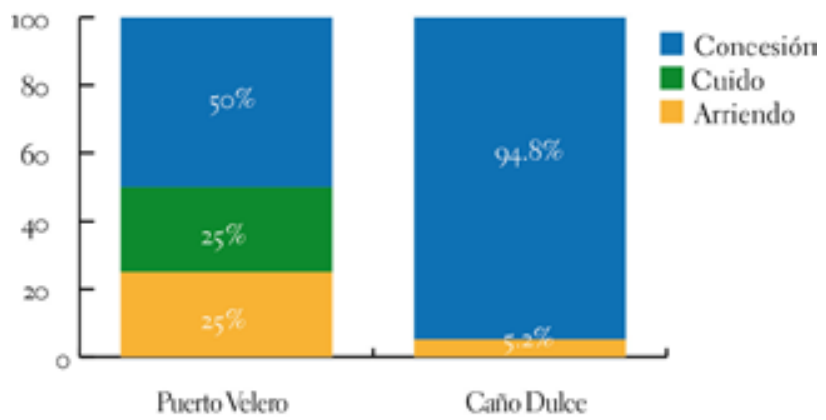

Figura 12. Posesión del inmueble

Con respecto al pago de impuestos en las playas, $82.1 \%$ de los prestadores turísticos pagan el impuesto de Industria y Comercio (figura 13). Puerto Velero, a pesar de tener los mayores aportes, es quien presenta el porcentaje más alto de evasión (20\%).

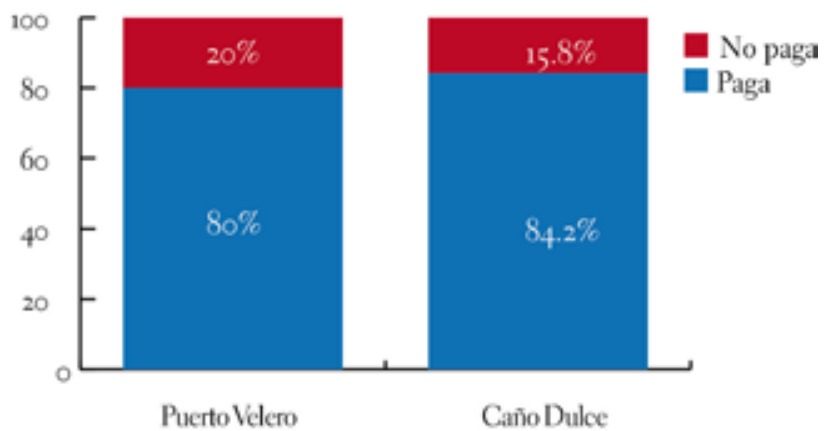

Figura 13. Pago de impuestos 
En relación con el impuesto, oscilan entre 0 y $\$ 400.000$ pesos (figura 14), lo que no fue posible determinar es el mecanismo para tasar este impuesto, pues los prestadores de servicios no manejan ningún tipo de facturación que permita medir sus ingresos, para ellos tampoco existe claridad en el proceso de liquidación de dicho impuesto.

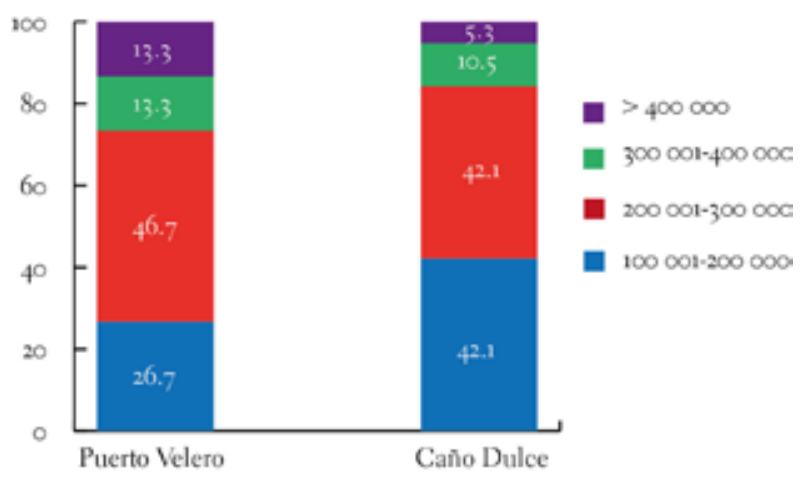

Figura 14 . Valor de impuestos

En cuanto al número de trabajadores en cada una de las playas, en Caño Dulce se encuentran 111 y en Puerto Velero 88 personas, esto incluye meseros, cocineros y administradores de las casetas. El análisis de la distribución de fuerza laboral por caseta (figura 15) demostró que el mayor porcentaje se encuentra entre cuatro y seis trabajadores (46.7\% en Puerto Velero), siendo el mínimo porcentaje, de uno a tres trabajadores por caseta.

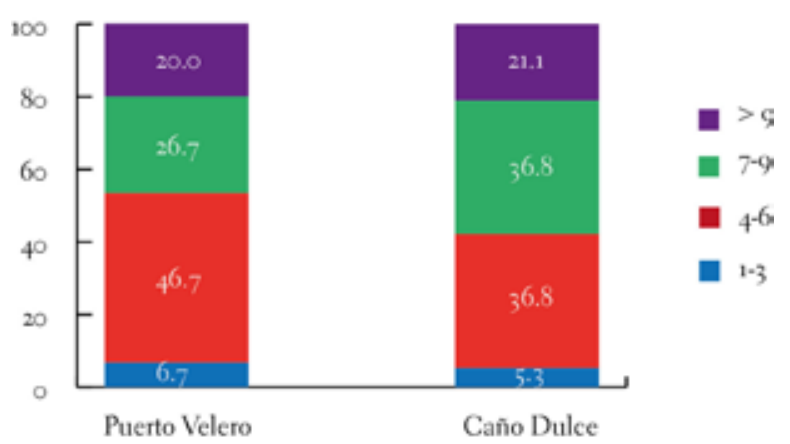




\section{Conclusión}

Las mediciones de oxigeno disuelto, en las dos playas estudiadas, mostraron valores aceptables de acuerdo con la normativa colombiana y criterios ecológicos internacionales, con datos registrados entre 3.75 y $8.61 \mathrm{mg} / \mathrm{L}$.

Con respecto a los sólidos suspendidos totales, en Caño Dulce en algunos casos el valor registrado en horas de la tarde es mayor que en horas de la mañana, mostrando la posible incidencia de la utilización de la playa por los turistas ya que ésta es una de las playas que más visitantes recibe. En cuanto a las grasas y aceites, se registraron valores muy elevados en los meses de octubre y noviembre en ambas playas. Se presume que estos valores tan altos están asociados a las prácticas de deportes náuticos, que por el uso de vehículos acuáticos desprenden combustibles y aceites en su funcionamiento.

En las dos playas hay presencia de coliformes fecales y totales pero ninguno de los registros sobrepasan los niveles permisibles por la normativa colombiana; sin embargo, esto es preocupante ya que los bañistas inevitablemente alcanzan a ingerir agua, corriendo el riesgo de que se generen daños a la salud. En términos generales, si se compara la calidad del agua de las playas de Puerto Velero y Caño Dulce con la normatividad colombiana, se puede decir que son playas que cumplen con los criterios exigidos con respeto a aguas de uso recreativo.

En cuanto al componente social en el estudio, es evidente la falta de presencia gubernamental que cumpla un papel organizador y regulador, lo que influye de manera puntual en la desmejora de las calidades ambientales y físicas del lugar. Es necesario la capacitación y preparación de los lugareños por parte de la alcaldía del municipio de Tubará para conformar una comisión de playa, agremiación que permitirá administrar y gestionar el atractivo, abordando los componentes ambientales, económicos y culturales del sector de Puerto Velero y Caño Dulce.

El manejo de los desperdicios y la falta de aprovechamiento del agua lluvia, por parte de los prestadores de servicio demuestra falta de instrucción y capacitación en estos comerciantes, que permitan un aprovechamiento del recurso 
hídrico y una mejor calidad en los servicios y menor deterioro de los recursos ambientales.

Los problemas en la posesión de los inmuebles y pago de impuestos denotan la falta de identidad y apego de los prestadores de servicios con su lugar y fuente de ingresos, lo que redunda en descuido en el mantenimiento de los inmuebles, falta de conciencia en la recolección de desperdicios y su disposición final, causando deterioros ambientales que repercuten en la calidad de agua y suelo en dichas playas.

Con el fin de prestar un buen servicio y preservación del ambiente en las playas, se recomienda implementar programas de uso eficiente del agua y manejo de residuos sólidos y líquidos, por lo que el agua y el suelo son los componentes ambientales más afectados por esta actividad. Debido a que es un trabajo que no tiene resultados inmediatos, requiere de un proceso de sensibilización que empieza con la capacitación y organización de los prestadores del servicio para lograr un cambio de actitud y de sentido de pertenencia hacia las playas. En estos programas se trabajarían aspectos como la segregación de residuos, la buena disposición final de los desechos que no se puedan reciclar o reutilizar, y con esto se mitigaría también gran parte de las emisiones por quema a cielo abierto; en cuanto a los residuos líquidos, se buscará evitar la contaminación del agua y arena de la playa, mediante su recolección, tratamiento previo y vertimiento controlado a través de un sistema de alcantarillado. El proceso se complementa con las campañas de sensibilización dirigidas a los usuarios o turistas haciendo énfasis en el manejo de los residuos sólidos y las buenas prácticas sanitarias en el uso de las playas.

\section{Literatura consultada}

American Public Health Association, American Water Works Association, APCF (1992). Métodos normalizados para análisis de agua y aguas residuales (17 ed.) Nueva York: American Public Health Association. Environmental Protection Agency (2003). Bacterial water qualitystandards for recreational waters (freshwater and marine waters) status report. Re- 
port EPA-823-R-03-008. Washington: Environmental Protection Agency Report.

García, M. A. y Martínez, R. E. (2008). Importancia de los organismos en la gestión de destinos: Caso del Centro Euromediterráneo de Conocimiento, Innovación y Formación Turística. Conferencia Internacional de Turismo: El conocimiento como valor diferencial de los destinos turísticos. Sesión 4, Gestión de Destinos. Málaga, España.

López, P., Salazar, S., Figueroa, Y., López y Fuentes, J. (2009). Calidad bacteriológica y fisicoquímica de aguas y sedimentos de cuatro playas de las costas del estado Nueva Esparta. Ciencia 17(4), 271-280.

MetCalf y Eddy (1995). Ingeniería de aguas residuales, vols. 1 y 2, España: McGraw Hill.

Ministerio de Agricultura (1984). Usos del agua y vertimientos líquidos. Decreto 1594, República de Colombia.

Ministerio de Comercio, Industria y Turismo (2011). Política de playas turísticas. Lineamientos sectoriales. Bogotá, Colombia.

Osorio, S. (2011). Diseño y organización de un modelo de playa de turismo sostenible que permita el crecimiento económico y beneficios socioculturales en la comunidad Mokaná, Tubará-Dpto Atlántico, Colombia. San José, Costa Rica.

Oyarzún, M. Edgardo y Szmulewicz, E. P. (1999). Fortalecimientos de la gestión en destinos turísticos. Gestión Turística. 4(1), 93-102. 